\title{
Communication and Cohesion among Family Members of Individuals with Substance Use Disorder in Iceland with a Focus on Adult Children of Addicts
}

\author{
Ólafsdóttir J*, Hrafnsdóttir S and Orjasniemi T \\ Department of Social Work, University of Iceland, Iceland and University of Lapland, Finland \\ Address correspondence to Ólafsdóttir J, jona@hi.is
}

Received 25 September 2018; Revised 27 October 2018; Accepted 01 November 2018

Copyright (C) 2018 Ólafsdóttir J, et al. This is an open access article distributed under the terms of the Creative Commons Attribution License, which permits unrestricted use, distribution, and reproduction in any medium, provided the original work is properly cited.

\begin{abstract}
Background. The aim of this research was to examine family cohesion and communication in families where one member has Substance Use Disorder (SUD). Do Icelandic family members of SUD report low communication and cohesion in their families? Are there significant differences between family members, such as spouses, parents, adult children, and siblings? And do family members express their feelings and experiences in a similar way? Methods. In this study, both quantitative and qualitative methods were used. The primary approach of the study utilized quantitative research methods to examine family cohesion and communication in families where one member has SUD. Two ten-item scales were used; the Family Communication Scale (FCS) and the Family Satisfaction Scale (FSS). The results of which led the researchers to interview four adult children of addicts in the second phase of the study. Qualitative methods were utilized so as to give the group of adult children of substance users a voice and in a hope to improve treatment methods specifically for this group. Results. The results indicate that the participants experienced low family cohesion and closeness overall, and they were concerned about family relations and the quality of their communication. Participants who had parents with SUD ranked family cohesion and communication lower compared to those who had a spouse/partner, siblings or children with SUD and became the basis for the second phase of the study. Conclusion and Applications. The results of this study can be used to improve and promote treatment for the whole family and for individual family members, especially adult children of SUD, and be used to better understand the effects of SUD on families and public health.
\end{abstract}

Keywords: substance use disorder, SUD, family therapy, family cohesion/satisfaction, adult children of addicts, family relations/ communication

\section{Introduction}

The objective of this research is to measure the extent that living with an individual afflicted by Substance Use Disorder (SUD) affects the psychosocial and behavioral state of other family members, especially communication and cohesion. Thus, this study focuses more on the psychosocial well-being of individuals rather than the physical effects of living in a family where SUD is present.

This study uses the term 'substance use disorder' as defined by the American Psychiatric Association [1] in its DSM-5 diagnostic manual. According to the canonical DSM-5 (Diagnostic and Statistical Manual of Mental Disorders, version 5), an individual is diagnosed with substance use disorder if two or more symptoms out of eleven apply to that individual during the past year [1]. The seriousness of the disorder is determined by how many of the eleven diagnostic criteria apply to that individual. If an individual is diagnosed with two to three symptoms from the reference list, the diagnosis would be mild substance use disorder. Four or five symptoms indicate moderate SUD. An individual is considered to have a serious substance use disorder if six or more symptoms are applicable.

A healthy self-image and self-esteem arise from interactions between family members where there is trust and intimacy. Children who grow up with intimacy and trust with their parents find it easier to trust others and to form close relationships in adulthood [2]. However, if a child grows up with a lack of trust and emotional intimacy with his/her care-givers-for example due to SUD of one or more members of the family-can result in the child feeling insecure in his/her relationships with others in adulthood. He/she can have difficulty forming relations with others, i.e. a relationship characterized by emotional intimacy, difficulty in trusting others and feeling secure relating to others, whether as a family or as a couple [3]. Studies have shown that adults in partnerships define intimacy and emotional attachment to one another by evaluating their partner's behavior towards themselves. It has also been observed that if couples feel they can 
resolve conflicts and disputes through negotiation it bodes well for good communication and contentment within the family. The relation between intimacy and communication in couples' relationships gives a certain indication of family contentment and cohesion [4,5]. Also, studies have shown that if there is little trust and a lack of emotional intimacy in a couple's relationship, it is more likely that spouses and children in the family will experience anxiety and less contentment in the family $[5,6]$. This research measures family cohesion and communication/relations in families where a family member has a SUD. It also examines whether the position of that person in the family makes a difference to family cohesion and communication/relations ${ }^{1}$. This study is an important contribution in international alcohol and drug research because most studies to date have focused on those who have SUD rather than on their family members. The results of the study can be used to improve and promote treatment for the whole family and for individual family members and be used to better understand the effects of substance dependence on families and public health.

1.1. The influence of substance use disorder on psychosocial wellbeing and communication/cohesion of family members

In a marriage or couple relationship individuals' distress can manifest itself in negative emotions such as anxiety or anger, which can result in avoiding difficult situations, such as intimacy and communication in a couple's relationship [4,6,7]. Research carried out in 2014 using the FACES IV self-evaluation scale and the FSS and FCS scales showed similar results. Family cohesion and relations were rated significantly lower for those families living with SUD than for those without. Klosterman et al. [8] compared two groups of secondary school age students, one group $(n=136)$ had a parent with a substance use disorder and the other group $(n=436)$ did not. The aim of the research was to examine whether individuals who had grown up with SUD showed more psychosocial symptoms of depression than those who had grown up in families with SUD. The results showed that those who had grown up with a parent with SUD had more behavioral issues and interpersonal problems, experienced more distress and had less insight into their well-being than the control group. The results also indicated that participants who had grown up with a parent with SUD were more likely to make emotional decisions and used more alcohol and/or other substances than those who had not grown up with parents suffering with SUD. These research results indicate that parents' SUD has an impact on how their children get on in adulthood, which also supports the research conclusions drawn by Springera, Sheridanb, Kuoc and Carnesb [9] and Skowron and Dendy [7]. Klosterman et al.'s findings

${ }^{1}$ With thanks to SÁÁ for their support with data collection and promotion of the research support the research results of Johnson and Stone [10] as well. They examined how children who grew up with a parent with a substance use disorder experience happiness as an adult in their relationship with a partner and also how they experience their role as parents. These results were compared with a control group who had grown up in a normal family environment. The former group reported a lack of communication and satisfaction in their relationship with their partner and in their relationships with their children. Significantly more of the control group reported that they were satisfied with their relations with their family. Other research has shown that adult children of parents with a substance use disorder do not always experience a lower quality of life than those who did not have parents with SUD [11-13]. So, it is not possible to claim that children who were brought up by a parent with SUD will always fare worse in terms of their mental health or their capacity to maintain healthy relationships in their adult years than children who have not been brought up by a parent with a substance use disorder.

\subsection{Adult children of substance users}

Children who grow up with their parents' substance dependence are at greater risk of being neglected by them. The definition of neglect is wide-ranging. A caregiver or parent who misuses alcohol or other drugs is less able to care for the mental and physical needs of the child. SUD creates instability and conflict in the child's environment. The parent lacks the ability to protect the child from various dangers, such as accidents in the home [14]. Children who grow up in these circumstances are at a higher risk of developing psychosocial problems [15]. They will often witness violence between their parents and may themselves be victims of mental, physical or sexual violence $[14,16]$.

Studies have shown and professionals have pointed out that adult children of dependent substance users grew up in homes where communication and relationships between family members were not normal and secrets about their family life abound [4,17]. The experience of keeping a secret to protect their parents while growing up can have a negative effect on bonding, intimacy and communication with others in adult years [4]. Substance dependence can result in family members experiencing high levels of guilt and shame. The family's unwritten rules are not to talk about it and not to say anything that might provoke the substance user, where they might fly off the handle and so use more alcohol or other drugs. This unhealthy pattern can reduce the quality of life for individual family members right through to adulthood and can prevent normal emotional connections, intimacy and communication in their interactions with others $[6,17]$.

A study was carried out based on a survey of two groups: individuals who had not grown up with substance dependence in the family and adult children of dependent 
substance users. On the one hand, the results showed that the behaviour of those who had not grown up with substance dependence was governed more by informed rational decisions rather than by emotional experience. On the other hand, behaviour and decisions of adult children of dependent substance users was governed more by their emotional attitude to issues rather than reasoning [7]. Those with a poor ability to distinguish between emotions and reasoning have a limited capacity to think critically. This can therefore lead to their emotional reactions and decisions being governed by stress responses $[6,19,20]$. Furthermore, this data supports the quantitative study carried out to evaluate the levels of satisfaction reported by adult children of dependent substance users in their couple relationships and roles as parents. The control group consisted of individuals who had grown up under normal circumstances. The first group reported a lack of pleasure and interaction in their couple relationship and in their interaction with their own children, whereas the control group reported significantly higher levels of pleasure in their interactions with the family [10]. The results of the study revealed that adult children of dependent substance users are more likely to experience anxiety and try to avoid difficult situations. Those participants who had grown up with substance dependence in the family showed significantly less ability to generate trust and intimacy in their relationships with others compared to the control group $[10,15]$. Other research has also shown that people who grew up with substance use disorder in the family find it significantly harder to build trust and intimacy in their relationships and experience less satisfaction in family relations than those without a chemically dependent family member $[4,18,21]$.

\subsection{Family therapy in families with dependent SUD}

At some point most families need to seek professional help for various issues. The professional may be a doctor, teacher, social worker, psychologist or nurse, who may offer personalized family services and/or counselling. When a family experiences a difficulty or illness which affects one family member a new pattern of interaction can arise within the family, which family members experience as a problem $[22,23]$.

The family is an independent social unit that plays a large part in creating a community and setting social norms. Each family has its own culture, identity and beliefs that must be taken into account when working with one for each family has its own rules, values and norms [24-26]. Family therapy is a collection of treatment approaches in which family bonds are pivotal and it is possible to restore those relationships with the right intervention when they have been distorted [27].

The individual is part of a whole and it is the interaction of the parts within the whole, i.e. the family, which shape the individual's life. Systems theory looks at behavioral patterns and systems rather than focusing on the individual. According to this theory, if one aspect of the system changes then everything within the system will change [28]. This approach attempts to identify what the individual has not perceived in the interaction within the family [29]. According to systems theory, family therapy focuses on this aspect of systems theory and uses the strength of the family to bring the family back into a healthy dynamic again [28].

This approach can also be used to treat families who struggle with the effects of SUD [28]. Whether it is a case of an adult or a teenager who is the substance user in the family it is important for the whole family to enter into therapy (SAMHSA, 2005) [27]. Since the family dynamic has been distorted, due to a parent's alcohol or drug use for example, children can take on the role of the adult. Teenagers and children can begin to take responsibility for younger siblings and start to have concerns about their parent's health. This can occur with children who have neither the age nor maturity to be responsible for themselves [11]. Critics of this approach have pointed out that therapy is provided for the whole family, which may not be an appropriate approach for the dependent substance user themselves. The reason this approach may not be appropriate is that the therapists focus too much on the family and not on the substance user who may need specialized, individually tailored treatment [30-32].

The development of treatment models for individuals with SUD had led to the field of family and couples' therapy becoming a major factor in intervention. The most widely used approach is based on the family disease model; i.e. substance use disorder affects all members of the family. The article by Alan Carr [33] entitled, the effectiveness of family therapy and systemic interventions for adult-focused problems, discusses the increased effectiveness of intervention and treatment for individuals who have SUD and, if or when the family is given support and treatment [30,33].

\subsection{Objective and methodology of this study}

The objective of this study was to explore the extent to which living with an individual afflicted by SUD affects family members' experience of communication and cohesion in their families. The chief questions addressed by this study are:

- Do Icelandic family members of SUD report low communication and cohesion in their families?

- Are there significant differences between family members, such as spouses, parents, adult children, and siblings?

- $\quad$ And do family members express their feelings and experience in a similar way?

In this study both quantitative and qualitative methods were used. Quantitative research methods were used in the primary approach of this study. The results of 
which led to the second part, where qualitative research methods were applied, to give a group of adult children of SUD a voice.

In the quantitative part of the study, two scales of measurement were used, the Family Communication Scale (FCS) and Family Satisfaction Scale (FSS). The FCS is intended to measure healthy relations within families and the FSS measures participants' experience of satisfaction within the family. Participants respond on a 5-point Likert scale from 1 (strongly disagree) to 5 (strongly agree). Higher scores on these two scales indicate higher levels of happiness in the family and better relations between family members. Higher scores on these two scales indicate higher levels of happiness in the family and better relations between family members. On the FCS participants can score between 10 and 50; their rating is reached by adding together the scores from the 10 questions on the scale. The families are then divided into 5 groups according to their rating. The lowest group has a rating between 10-29 and this group is very concerned about the quality of their family relations. The next group has a rating between 30-35 and they are concerned about the quality of their family relations. The group rated between $36-39$ is generally satisfied with their family relations but have some concerns. The group with a rating between $40-43$ is generally satisfied with their family relations and has few concerns, and the highest rating is 44-50 and this group experiences very positive family relations. The FSS has a similar rating system to the FCS. Those who score 10-29 are very dissatisfied and have concerns about their family, the next rating is $30-35$ and this group is rather dissatisfied and has some concerns about their family. The middle rating is 36-39 and this group is reasonably satisfied with family relations and enjoys their family to some extent. Those with a rating of 40-44 are to a large extent satisfied with their family and those with the highest rating, 45-50, are very satisfied with their family in most respects.

Alpha coefficients, which evaluate the internal stability of FCS and FSS, are based on responses from 2,465 family members in research carried out in the United States during the 1980s to develop the measures $[34,35]$;. Reliability and validity coefficients of the measuring device examine the expected results of the FCS and FSS as part of the Family Adaptability and Cohesion Evaluation Scales (FACES) IV, which is the newest edition of the scale that measures cohesion, adaptability and communication skills in families. These three elements are also the three main elements in the Circumplex Model of Marital and Family Systems on which FACES IV is based [36].

These methods were used to assess the influence a person's SUD has on other members of the family. Purposive samples were used to choose participants. The questionnaire was administered to 252 clients (24\% men and $76 \%$ women) in family therapy at the Icelandic
National Centre for Addiction Treatment (SÁÁ) from October 2014 - June 2015 and August 2015-May 2016. All participants received the questionnaire at the start of their group treatment and the response rate was $100 \%$. The SÁÁ bioethics and scientific committees granted permission for the research project.

All statistical analyses were carried out using SPSS (Statistical Package for Social Science); descriptive statistics were used to describe all parameters of the study including demographics of gender, age and marital status. ANOVA was used to compare responses on the FCS and FSS to average scores and to see whether differences were detected depending on which family member presented with a chemical dependence: a parent, sibling, partner, or child.

The qualitative part of the study was carried out in the spring and summer of 2016, when the results of the quantitative component became available. The adult children of SUD scored lower on both the FCS and FSS than parents, spouses and siblings. These results created the basis of the second part of the study, focusing on the experiences of these adult children of SUD using qualitative research methods. The researcher gathered descriptive data, verbal descriptions from adult children (sources) of parents with SUD and descriptions of observable responses [37,38]. For this purpose, 4 in-depth interviews were conducted with selected individuals, two men and two women. Adult children of SUD were selected from a group of families with one or more dependent with SUD and who were not affected by SUD themselves. The so-called snowball method was used, in which research participants recruit others to become additional participants for the study $[37,38]$. Interviews took place in the participants' homes or the researcher's office, and the duration was on average 50 min. The interviews were open-ended, semi-structured [39] and based on an interview guide. The interviews focused on participants' experiences and the impact their parent's SUD had on their everyday lives with regards to communication and cohesion during childhood and adolescence. Additionally, they were asked about their experiences of service needs and if they were offered or provided. All interviews were digitally recorded, transcribed and analyzed with systematic text condensation, a crosscase method for thematic analysis [40].

\section{Ethics and Limitations of this Study}

In all research, there are limits to the tools used. In this case, the data size in the quantitative part of the study is relatively small $(n=252)$, which may not reflect the experiences of all individuals in Iceland who have family members afflicted with SUD. Nonetheless, the findings can provide an indication of the mental health effects experienced by this sub-group within society.

From an ethics perspective, none of the participants were currently in therapy for their own SUD, and none 
were under the age of 18 . The survey was anonymous, and all documents were properly destroyed at the conclusion of the evaluation. The identifying information was encrypted so the data could not be traced to the participants of the study and was deleted after processing and analysis. The Icelandic National Bioethics Committee and the Research Committee of the Icelandic National Centre for Addiction Treatment (SÁÁ) each granted permission for this project.

There are two limitations to the qualitative phase of the study: first, the relatively small number of people interviewed ( $\mathrm{n}=4 ; 2$ men and 2 women); and second, the same researcher carried out all of the interviews, analyses, and interpretation of the data. Participants in the qualitative phase were offered the option of one therapy session with the professional free of charge, to the best of our knowledge none of the participants accepted this offer. Since all of the participants in the quantitative phase of the study were already enrolled in a therapy group, they were not offered additional therapy. Further, the applicability of this qualitative study to society as a whole may be limited by the fact that the same researcher carried out all of the interviews, analysis, and interpretation of the data. Nonetheless, the study does provide some insight into how family members, who live with SUD sufferers, express their communication and cohesion in their family, especially since they are given a voice to describe those impacts via the interview process.

\section{Results}

In the primary part of the quantitative study 252 individuals participated, all of them taking part in family group treatment at SÁÁ. The group consisted of 59 men (24\%) and 192 women (76\%). One of the participants did not record their gender and three did not record their age. Not all of the participants responded to every question on both the FSS and FCS questionnaires and this was accounted for in the statistical analysis. The majority of the participants $(82 \%)$ lived with their partner and/ or children, $11 \%$ lived alone and $7 \%$ lived with their parent/s. The average age of the participants was 47.1 years $(\mathrm{SD}=13.9)$, with the oldest participant being 81 years old and the youngest 19 . The participants were divided into the following age groups to simplify the statistical analysis: 35 years old and younger, 36 to 45 years old, 46 to 55 years old and 56 years old and older. Most of the participants, or $67.2 \%$, were aged 46-55. Most of the participants, or $40 \%$, who attended family group therapy were parents who had a child with SUD, $32 \%$ of the participants came because of their partners and $20 \%$ attended because of their parents. Only $8 \%$ attended because they had a sibling with a dependency.

The influence of SUD on family cohesion and family relations/communication

Table 1 shows the participants average on the FSS was 33.0 points, STD 6.9 and with alpha reliability of .893 .

Averages marked with different letters proved to be different according to the Bonferroni method $(\alpha=0.05)$

Table 1 shows the participants average on the FSS was 33.0 points, STD 6.9 and with an alpha reliability of .893. There was a difference between the groups $(\mathrm{F}(3.248)=4.530, \mathrm{p}=0.004)$. Post hoc comparisons using the Bonferroni correction revealed that those participants that attended the family group therapy because of a parent scored lower than those that came because of a partner and a child. This shows that the adult children of parents with SUD felt a greater lack of satisfaction in their family than the other groups; partners, parents and siblings.

Table 2 shows the mean score on the FCS scale was 32.8 , STD 7.69, with an alpha reliability of .890 .

A One way ANOVA showed that there was difference between the participants when grouped after what family member was addicted $(\mathrm{F}(3.248)=3.351, \mathrm{p}=0.020)$. Post

Table 1: One-way ANOVA on reported responses to the family satisfaction scale.

\begin{tabular}{|c|c|c|c|c|c|}
\hline \multirow[b]{2}{*}{ Family member } & \multirow[b]{2}{*}{ Mean } & \multirow[b]{2}{*}{ Std dev } & \multicolumn{3}{|c|}{ 95\% confidence interval } \\
\hline & & & Lower limit & Upper limit & $\mathrm{n}$ \\
\hline Parent & $30.38_{\mathrm{a}}$ & 6.52 & 28.53 & 32.23 & 50 \\
\hline Sibling & $30.53_{\text {a.b }}$ & 6.07 & 27.60 & 33.45 & 19 \\
\hline Partner & $33.89_{b}$ & 6.71 & 32.40 & 35.37 & 81 \\
\hline Child & $33.97_{b}^{b}$ & 7.00 & 32.60 & 35.35 & 102 \\
\hline Total & 32.97 & 6.89 & 32.12 & 33.83 & 252 \\
\hline
\end{tabular}

Averages marked with different letters proved to be different according to the Bonferroni method $(\alpha=0.05)$

Table 2: One-way ANOVA on reported responses to the family communication scale.

\begin{tabular}{|c|c|c|c|c|c|}
\hline \multirow[b]{2}{*}{ Family member } & \multirow[b]{2}{*}{ Mean } & \multirow[b]{2}{*}{ Std dev } & \multicolumn{3}{|c|}{$95 \%$ confidence interval } \\
\hline & & & Lower limit & Upper limit & $\mathrm{n}$ \\
\hline Parent & $30.04_{\mathrm{a}}$ & 7.16 & 28.00 & 32.08 & 50 \\
\hline Sibling & $31.47_{\mathrm{a} . \mathrm{b}}$ & 6.43 & 28.37 & 34.57 & 19 \\
\hline Partner & $33.28_{\text {a.b }}$ & 8.14 & 31.49 & 35.08 & 81 \\
\hline Child & $33.99_{b}$ & 7.51 & 32.51 & 35.47 & 102 \\
\hline Total & 32.79 & 7.69 & 31.84 & 33.74 & 252 \\
\hline
\end{tabular}

Averages marked with different letters proved to be different according to the Bonferroni method $(\alpha=0.05)$ 
hoc comparisons using the Bonferroni correction showed that those that attended the family group therapy because of their parents scored lower than those that came because of their child. This shows that the adult children of parents with SUD felt a greater lack of communication in their family than the other groups; partners, parents and siblings.

\section{Qualitative Phase of the Study}

The participants in the qualitative part of the study were chosen with purposive sampling, where participants have grown up with a parent(s) with SUD. All the participants were aged nineteen to thirty years old. There were two women and two men interviewed, three of them had grown up with their mother's SUD and one with a father who had a drinking problem. Two had grown up with both biological parents, two only with their mother. One of the participants had struggled with SUD herself. All the participants had older and/or younger siblings, all of them had experiences of intimate relationships and three had a spouse. Two of the participants had one child, one had two children and one had no children. Together these participants reflect the purpose of the second part of the study i.e. to give adult children voice about their experiences of cohesion and communication within families with parents suffering of SUD.

The following emerged, all the interviewees except one felt anxious and depressed and had sought professional help. All of the adult children reported having trouble with communicating in their own close relationships, because they did not know how they themselves felt. They had trouble understanding their own feelings and feared rejection. All participants began to take responsibility early in life; for example, their schooling and leisure. Two of the participants had lived under the poverty line as a child. These two had to move often or were often homeless. As one of the interviewees said:

[... I remember when I was stealing toilet paper, soap and other things that could be taken from school because we could not buy it, because all the money my mother received went to her drugs and alcohol...I was so ashamed for myself and my mother and tried to hide this from my friends and never spoke about my family to them...]

Half of the interviewees reported being dishonest when communicating with their spouses even though there was no reason for not telling the truth. As one interviewee said:

[... I went and visited my acquaintance at his workplace that he had recently opened, it's a computer workshop, and when my partner asked where I'd been, I told her I'd been at work even though it didn't matter. I'd visited this friend of mine ... I thought about it afterwards. Why didn't I tell her where I was? I mean there must be something wrong with me...?]
Most of the interviewees mentioned that they had not experienced a real feeling of joy and happiness in adulthood, except for two of them, who said they experienced real joy when their children were born, but they also felt a heavy load of responsibility. As one of the participant reflects similarly to the others in the group:

[... for example, during holidays I don't think I have ever felt the same excitement and the same joy as I have heard other people talk about, only anxiety and stress... even though there is nothing in my life to worry about right now. I can feel how it's impacted my spouse. She is constantly asking me if there is something wrong. And then I get more annoyed and all of the sudden we start arguing ...]

The participants were asked if they had sought professional treatment (i.e. private counselling with therapist) to work through their experiences of growing up with an addict parent and only one participant reported they had not. All agreed it is something that is necessary. One of the participants stated:

[...I think it's necessary to provide professional therapy for adult children of addicts. In therapy like that you can talk to other people with the same experience and everybody knows what you are talking about and they understand your feelings. I am not talking about self-help groups like ALANON or mixed groups with other relatives of addicts with professional counselling. It is just not the same; you know one size does not fit all. And I think I would enjoy my life better and be a better spouse if I could learn to understand my negative feelings and sometimes my reactions as well...]

\section{Discussion}

The results showed that participants scored an average of 33.0 on the Family Satisfaction Scale (FSS), which indicates that family members felt dissatisfaction and discord within the family and were concerned about their family unit. Some participants scored an average of 32.8 on the Family Communication Scale (FCS), which tells us that family members have some concerns about the quality of communication within their family. These results are somewhat lower on both scales (FSS and FCS) than the results revealed in the research of Olson et al. $[35,36,41]$. There the FSS score was $37.5(\mathrm{SD}=8.5)$ which means that family members were reasonably satisfied and content and enjoy some aspects of their family life. Their results on the Family Communication Scale were slightly lower, on average 36.2 ( $\mathrm{SD}=9.0$ ), which means that family members have some concerns about communication within their family. These results reveal that SUD in one family member has an influence on the other family members and affects how satisfied they are about their family and about communication within the family. The results of this study support the research carried out by Margasinski [21] using the same FSS and FCS questionnaires as this study. 
By using a one-way ANOVA it is possible to see that the mean on both the FSS and FCS differed depending on which family member had a SUD. The results of both scales showed that participants, who attended family therapy because they had a parent with a dependency, experienced less family cohesion and poorer communication in their family than those with a partner, child or sibling with a dependency. To gain a deeper understanding of these quantitative findings the researcher took four depth interviews with participants who were not taking part in the family group therapy. They were asked about their childhood experiences and the impact of their parent's substance use on their everyday life, especially in regards to communication and cohesion during childhood and adolescence. They were asked about experiences of service needs and if they were offered or provided. All of the participants thought they were having trouble communicating in their own close relationships, because they had trouble understanding their own feelings and feared rejection. Everyone took responsibility of their schooling and leisure early in life. All the interviewees mentioned that they did not experience a real feeling of joy and happiness in adulthood. The participants were asked if they had sought professional treatment (i.e. private counselling with a therapist) to work through their experiences of growing up with a parent with SUD and only one had not, but all agreed it is something that is necessary.

It is interesting to note that grown-up children of parents with a SUD experience little satisfaction with their own family and a lack of communication between family members. This supports the research of Skowron and Dendy [7], Sunday et al. [14] and Springera et al. [9] that adult children of parents with a dependency can have trouble in family relations. This also reflects the results found by Johnson and Stone [10], mentioned above, which showed that those who were brought up by a parent with SUD experience less satisfaction and communication with their partner and their children than a control group.

The limitations of this research are that the sample size was small so it is not possible to conclude that everyone who lives with SUD in the family will experience limited family cohesion and poor communication within the family [11]. However, it can be argued that this is more likely to be the case in families with SUD. According to the participants in the qualitative part of the study, it would be worthwhile to split those attending family therapy into groups according to which member of their family has a dependency. Those who have grown up with a parent with a SUD have difficulty with relationships and communication in their adult years, according to research $[2,7,10]$ and would perhaps benefit from a different kind of therapy and support than is offered by current forms of group therapy for those with a family member with a SUD. The influence of SUD on families warrants further research, for example by carrying out a comparable research project with a larger sample that also asks participants about their mental well-being, with reference to stress, anxiety and depression. There is also a need for better research into the short and long-term effects of growing up with SUD in the family, particularly with respect to prevention. It would also be valuable to ask those attending family therapy to fill in the FSS and FCS at the beginning and end of therapy to examine whether this form of therapy results in better family cohesion and communication.

\section{Conclusion: Applications}

In general, the results of this study can be used to improve and promote treatment for the whole family, taken as a unit, as well as for individual family members, and can help social professionals to better understand the effects of substance dependence on families, family systems, and public health in general.

The ability to apply the findings reported here is limited by the relatively small data size both of the quantitative and qualitative phases, which in turn limits the ability to extrapolate that most people who have lived with a family member affected by SUD will be found low communication and cohesion in their families.

An especially interesting follow-up to this study would be to examine the relatives with SUD, using the same procedures developed for this study, to learn how they express their experiences and feelings. (By using the same procedures, the ability to compare results would be enhanced.) Learning the ways in which the relationship between the relative with SUD and the parents, children, siblings, or spouses are parallel in both directions, especially regarding negative feelings, could lead to more individualized family therapy that would support the recovery of both for the SUD and the family as whole.

Further research is needed on the effects of growing up in Iceland with a parent who has SUD, considering the discrepancy found in this study and others $[10,15]$. Such additional research could sharpen our understanding of the Icelandic experience and could help us understand whether an upbringing associated with SUD is correlated with depression among siblings and children in their younger years, and with consumption of alcohol and other drugs in their adult years. Such additional research could be especially valuable in efforts to measure and manage national health and to develop preventive measures. Arguably, research on adult children of SUD over the last decades continues to show the same similar results regarding the quality of life and lack thereof for these adult children, which is interesting from a therapeutic perspective. Why have we been unable to create resources for these children who grow up with parents of SUD, before they become adults? Studies such as this one should help therapists, activists and researchers across fields and disciplines from social work, to sociology, psychology and criminology to 
name a few. This study's most important finding, by far, is that all family members tend to suffer when one family member is afflicted by SUD. It is imperative that clinicians appreciate the need to treat the family as a whole, and to begin to do so as early as possible. To do so not only benefits the family member who suffers from SUD but can also serve as a preventative measure for the next generation.

\section{References}

[1] American Psychiatric Association, Diagnostic and Statistical Manual of Mental Disorders (4th edition) known as DSM-V, (2013).

[2] E. L. Park, J. Crocker, and D. K. Mickelson, Attachment styles and contingencies of self-worth. Pers Soc Psychol Bull, 30 (2004), 1243-1254.

[3] M. Mikulincer, and P. R. Shaver, Attachment in adulthood: Structure, dynamics, and change. New York (2007): Guilford Press.

[4] S. Hrafnsdóttir and J. M. Ólasdóttir, Vimuefnafikn, samskipti og fjölskylduáncegja. Tímarit félagsráogjafa, 10, (2016), 12-18.

[5] K. Dumont, D. Jenkins, V. Hinson, and G. Sibcy, God's shield: The relationship between god attachment, relationship satisfaction, and adult child of an alcoholic (ACOA) status in a sample of evangelical graduate counseling students. J Psychology and Christianity, 31 (2012), 51-65.

[6] J. Ólafsdóttir, S. Hrafnsdóttir, and T. Orjasniemi, Depression, anxiety, and stress from substance-use disorder among family members in Iceland. Nordic Studies on Alcohol and Drugs. First Published May 29(2018).

[7] E. A. Skowron, and A. K. Dendy, Differentiation of self and attachment in adulthood: Relational correlates of effortful control. Contemporary Family Therapy, 26 (2004), 337-357.

[8] K. Klosterman, R. Chen, M. L. Kelley, V. M. Schroeder, A. L. Braitman, T. Mignone et al., Coping behavior and depressive symptoms in adult children of alcoholics. Subst Use \& Misuse, 46 (2011), 1162-1168.

[9] K. W. Springera, J. Sheridanb, D. Kuoc and M. Carnesb, Longterm physical and mental health consequences of childhood physical abuse: Results from a large population-based sample of men and women. Child Abuse \& Neglect, 31 (2007), 517-530.

[10] P. Johnson, and R. Stone, Parental alcoholism and family functioning: Effects on differentiation levels of young adults. Alcohol Treatment Quarterly, 27, (2009), 3-18

[11] J. R. Haber, K. K. Bucholz, T. Jacob, J. D. Grant, J. F. Scherrer, C E. Sartor, et al., Effect of paternal alcohol and drug dependence on offspring conduct disorder: Gene-environment interplay. J Stud Alcohol Drugs, 71 (2010), 652-663.

[12] M. E. Hunt, A comparison of family of origin factors between children of alcoholics and children of non-alcoholics in a longitudinal panel. Am J Drug Alcohol Abuse, 23 (1997), $597-$ 613

[13] K. J. Sher, Psychological characteristics of children of alcoholics. Alcohol Health Res World, 21 (1997), 247-254.

[14] S. Sunday, M. Kline, V. Labruna, D. Pelcovitz, S. Salzinger and S. Kaplan, The Role of adolescent physical abuse in adult intimate partner violence. J Interpersonal Violence, 26 (2011), 3773-3789.

[15] L. Kestilä, T. Martelin, O. Rahkonen, K. Joutsenniemi, S. Pirkola, K. Poikolainen et al., Epidemiology and prevention. Childhood and current determinants of heavy drinking in early adulthood. Alcohol \& Alcohol, 43(2008), 460-469.
[16] R. Velleman, L. Templeton, D. Reuber, M. Klein, and D. Moesgen, Domestic abuse experienced by young people living in families with alcohol problems: Results from a cross-European study. Child Abuse Review, 17 (2008), 387-409.

[17] L. M. Kelley, A. French, K. Bountress, A. H. Keefe, V. Schroeder, $\mathrm{K}$. Steer, et al., Parentification and family responsibility in the family of origin of adult children of alcoholics. Addict Behav, 32 (2007), 675-685.

[18] T. Orjasniemi, and Kurvinen A, Häpeän päivät, pelon yötLapsuuden kokemuksia ongelma-juovista vanhemmista [Days of shame, nights of fear. Childhood Experiences of a Life with Alcoholic Pa-rents]. Janus, 25 (2017).

[19] K. Blum and D. W. Sherman, Understanding the experience of caregivers: a focus on transitions. Seminars in Oncology Nursing, 26 (2010), 243-258.

[20] C. P. Bowen and L. D. Riley, The sandwich generation: Challenges and coping strategies of multigenerational families. Fam J, 13 (2005), 52-58.

[21] A. Margasinski, An Outcome study of alcoholic families in Poland using FACES IV. J Fam Psychother, 25 (2014), 348-358.

[22] J. M. Ólafsdóttir, and S. Hrafnsdóttir, Fjölskyldan og vímuefnasýki [Family and addiction] (2011).

[23] M. Rivett, and E. Street, Family Therapy. 100 Key points \& Techniques (2009). New York: Routledge.

[24] H. Hårtveit, and P. Jensen, Familien-pluss én. (2nd edition) (2004). Oslo: Universitsforlaget.

[25] S. Júlíusdóttir, Fjölskyldur við aldahvörf. Náin tengsl og uppeldisskilyrdi barna. [Families at the turn of the century. Intimate relations and children's upbringing conditions]. Reykjavík (2001): University press.

[26] G. M. Barnes, Impact of the family on adolescent drinking patterns. In R. L. Collins, K. E. Leonard \& J. S. Searles (eds.), Alcohol Fam, (1990) New York: Guilford Press, Inc.

[27] U.S. Department of health and human services [SAMHSA]. (2005). $2^{\text {nd }}$ edition. Substance abuse treatment and family therapy. DHHS publication. Nr. 05-4006. Rockville: author.

[28] L. Lander, J. Howsare, and M. Byrne, The Impact of Substance Use Disorders on Families and Children: From Theory to Practice. J Soc Work Public Health, 28 (2013), 194-205.

[29] V. Satir, The new peoplemaking. California: Mountain View. Science and Behavior (1988), Books. Inc.

[30] H. E. Doweiko, Concepts of Chemical Dependency ( $9^{\text {th }}$ edition) (2015), USA: Thomson Brooks/Cole.

[31] In Halldór Sig. Guðmundsson (Ed.) Pjóðarspegillinn XII [Research in Social Sciences]. Reykjavik, Iceland: University of Iceland Press.

[32] D. C. Chaudron and D. A. Wilkinson, Theories on alcoholism. $2^{\text {nd }}$ edition (1998), Addiction Research Foundation. Toronto, Canada

[33] A. Carr, The effectiveness of family therapy and systemic interventions for adult-focused problems. J Family Therapy, 31 (2009), 46-74

[34] Y. Lavee, and D. H. Olson, Family Types and Response to Stress. J Marriage Fam, 53 (1991), 786-798.

[35] D. H. Olson, and D. M. Gorall, FACES IV \& the Circumplex Model, (2006).

[36] D. Olson, FACES IV and The Circumplex Model: Validation study. J Marital Fam Ther, 37 (2011), 64-80.

[37] L.W. Neuman, Social Research Methods: Qualitative and Quantitative Approaches. London (2014): Pearson. 
[38] D. K. Padgett, Qualitative methods in social work research (Second Edition). Thousand Oaks: Sage Publications (2008).

[39] S. Kvale, InterViews. An introduction to qualitative research interviewing. Thousand Oaks (1996), CA: Sage.
[40] K. Malterud, Systematic text condensation: A strategy for qualitative analysis. Scand J Public Health, 40 (2012), 795-805.

[41] D. H. Olson, Circumplex Model VII: Validation Studies and FACES III. Family Process, 25 (1986), 337-351. 